\title{
WEAR BEHAVIOUR OF AL-7075 COMPOSITES REINFORCED WITH BORON CARBIDE
}

\author{
KRISHNA MOHAN SINGH and A. K. CHAUHAN \\ Mechanical Engineering Department, K.N.I.T., Sultanpur, (U.P.) 228118, India
}

\begin{abstract}
Lightweight and high-performance materials are required for the application in the automobile, aerospace, and aircraft industries. The lightweight material can be obtained by developing composites by adding hard reinforcement particulates in the matrix of soft material. In this investigation, composites have been developed with varying weight\% (6, 8, 10, and 12) of $\mathrm{B}_{4} \mathrm{C}$ in the matrix of Al7075. The mechanical properties and wear behaviour of the composites were determined. Tensile strength and hardness were increased with an increase in weight\% of the reinforcement. The wear rate was increasing with an increase in the sliding velocity at constant load. However, the increase in wear rate at velocities from $1.5 \mathrm{~m} / \mathrm{s}$ to $2.5 \mathrm{~m} / \mathrm{s}$ was decreasing with an increase in the weight\% of the reinforcement.

KEYWORDS: Al7075 Alloy, Micro B4C, Stir Casting, Pin-on-Disc Rotary Tribometer
\end{abstract}

Received: Jun 06, 2020; Accepted: Jun 26, 2020; Published: Aug 31, 2020; Paper Id.: IJMPERDJUN2020968

\section{INTRODUCTION}

The Automobile, aircraft, and aerospace applications require the use of lightweight and high performance of aluminium alloy-based metal matrix composites. Such requirements can only be met by the development of aluminium alloy metal matrix composites. The composites with reinforcement particles can be manufactured through various processes such as stir casting, squeezed casting, spray deposition, powder blending, and consolidation, in-situ processing. The aluminium alloy based composites reinforced with boron carbide particles provide excellent strength, stiffness, hardness, wear resistance, and stability at high elevated temperature[1].

There are some challenges in the development of these composites, and these are controlling microstructure and mechanical properties, cost of the product through optimum composition, method of manufacturing, and heat treatment[2]. From the literature review, it is revealed that most of the previous work was done to reinforce $\mathrm{SiC}$ and $\mathrm{Al}_{2} \mathrm{O}_{3}$ particles in the matrix of the aluminium alloy.

Suresh et al. have prepared $\mathrm{Al} 7075 / \mathrm{Al}_{2} \mathrm{O}_{3} / \mathrm{SiC}$ hybrid metal matrix nanocomposites (HMMNCs) by the stir casting method. They examined the micro-hardness and wear behaviour and found that wear properties like wear rate and friction coefficient of $\mathrm{Al} 7075$ were decreased with the increase in $\mathrm{Al}_{2} \mathrm{O}_{3}$ and $\mathrm{SiC}$ powder and also with an increase in sliding velocity; micro-hardness value increased with an increasing weight percentage of the reinforcement[3].

In an investigation, Rajesh et al. have formed $\mathrm{Al} 7075-\mathrm{SiC}_{\mathrm{Al}} \mathrm{A}_{2} \mathrm{O}_{3}$ composites with various weight fraction of $\mathrm{SiC} / \mathrm{Al}_{2} \mathrm{O}_{3}$ by the stir casting. They observed the effect of heat treatment on mechanical characterization and wear 
behaviour and found that the age-hardened $\mathrm{Al} 7075-\mathrm{SiC}_{2} \mathrm{Al}_{2} \mathrm{O}_{3}$ composites showed excellent resistance to wear as compared to as-cast hybrid composite[4].

Bala Kumar et al. developed Al6061 composite with reinforcement particulates of fly ash, graphite powder, and copper powder by the stir casting method. They investigated microstructure, wear, and friction characteristics and optimized the experimental results by Taguchi's technique. They reported that the hardness of Al6061/fly ash $/ \mathrm{Cu} / \mathrm{Gr}$ composites was increased with the increasing weight percentage of the reinforcement. Both the frictional force and wear rate have decreased considerably with the weight percentage of reinforcement[5].

Daniel et al. prepared A15059/SiC/MoS 2 hybrid metal matrix composites by stir casting method. They examined the microstructure and dry sliding wear and optimized the results by the ANOVA test. They reported that load and percentage of reinforcement are the most affecting factors for wear rate and $15 \%$ of SiC of size $10 \mu \mathrm{m}$ offered better wear resistance and lower friction coefficient in Aluminium Hybrid Metal Matrix Composites[6].

Radhika and Priyanka have fabricated Aluminium alloy reinforced with Zirconia (10 wt.\%) by using the stir casting technique. The adhesive wear test was done on the prepared specimen using a pin-on-disc tribometer and was optimized by Taguchi's method. They found that the wear rate has a direct variation with applied load and inverse variation with sliding distance and sliding velocity. They reported that applied load (73.83\%) has a major impact on wear characterization [7].

Lara et al. fabricated Al7075-Graphite composites by mechanical alloying and hot extrusion process. They examined the microstructural and wear behaviour of the composites and found that this fabrication method produced notable grain refined; wear resistance of pure aluminium followed a linear relation with (grain size) $)^{-1 / 2}$. Strength and hardness of composites increased as a direct function of milling time and Graphite content[8].

Rao et al. prepared A17075/TiC composites by the stir casting technique. They examined wear behaviour of the composites and surface morphologies of the wear surfaces and concluded that with an increase in the percentage of the reinforcement, the wear resistance decreased. They further reported that wear appears to be decreased under the constant velocities at different sliding distances with increased weight $\%$ of the reinforcement, whereas weight loss increases notably with an increase in applied load[9].

Ravikumar et al. have fabricated $\mathrm{Al} 7075 / \mathrm{Al}_{2} \mathrm{O}_{3} / \mathrm{SiC}$ hybrid composites by the stir casting method. They investigated the mechanical and wear behaviour of the composites and obtained the optimum values for hardness for SiC: $9 \%$, Heat Treatment Temperature: $180^{\circ} \mathrm{C}$, and for wear rate SiC: $3 \%$, Heat Treatment Temperature: $140{ }^{\circ} \mathrm{C}[10]$.

Chandra et al. developed A17075 alloy composites reinforced with Albite particulate by the stir casting method. They found that hardness of A17075-Albite particulate composite increased for the reinforcement up to $8 \mathrm{wt} . \%$ and there was a decrease in hardness of the composite with the further addition of Albite particulates[11].

Radhika and Raghu manufactured LM 13 Aluminium/ $\mathrm{B}_{4} \mathrm{C}$ metal matrix composites synthesized by means of the liquid metallurgy technique. They investigated the wear behaviour of the composites and concluded that the wear behaviour increased with the increasing load and decreased with increasing velocity, sliding distance, and wt.\% of reinforcement[12].

In the present work, Al7075- $\mathrm{B}_{4} \mathrm{C}$ composite with $6,8,10$, and $12 \mathrm{wt.} \%$ of $\mathrm{B}_{4} \mathrm{C}$ particles (average size $50 \mu \mathrm{m}$ ) were fabricated through the stir casting process. To determine the wear, wear behaviour of Al7075- $\mathrm{B}_{4} \mathrm{C}$ composites was performed on a pin-on-disc rotary tribometer. 


\section{Nomenclatures}

- $\mathrm{Al} 7075$

- $\mathrm{B}_{4} \mathrm{C}$

- $\mathrm{M} 0$

- M6

- $\quad \mathrm{M} 8$

- $\mathrm{M} 10$

- $\mathrm{M} 12$

Abbreviations

- $\quad$ ANOVA

- HAMMCs

- $\quad$ HMMNCs
Aluminium Alloy 7000 Series

Boron Carbide

Pure Al7075

Al7075-6 wt.\% of $\mathrm{B}_{4} \mathrm{C}$

Al7075-8 wt. $\%$ of $\mathrm{B}_{4} \mathrm{C}$

Al7075-10 wt.\% of $\mathrm{B}_{4} \mathrm{C}$

Al7075-12 wt.\% of $\mathrm{B}_{4} \mathrm{C}$

\section{EXPERIMENTAL PROCEDURES}

\section{Selection of Materials}

For the fabrication of the composites, $\mathrm{Al} 7075$ is considered as matrix and $\mathrm{B}_{4} \mathrm{C}$ particles are considered as reinforcement as reported in our previous paper[13].

\section{Fabrication}

The composites under consideration are fabricated by using a stir casting technique. A vacuum furnace, as shown in Fig. 1 is used for the casting of the composites[13].

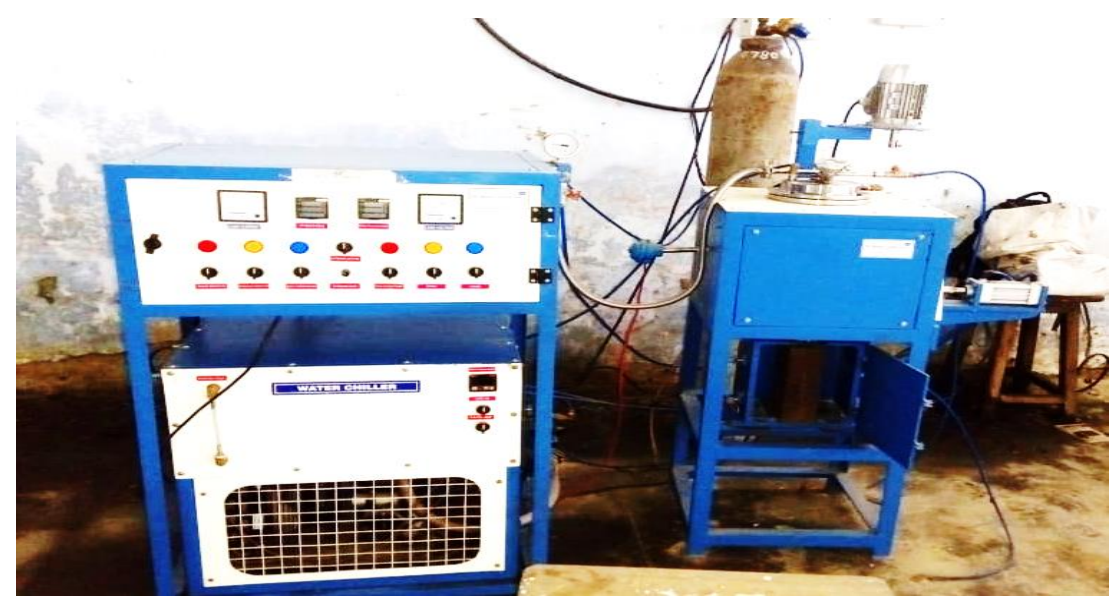

Figure 1: Vacuum Furnace.

\section{Mechanical Properties}


The tensile strength, impact strength, and hardness tests are conducted on the universal testing machine, impact testing machine, and Brinell hardness tester respectively.

\section{Density}

The density of the composites is measured by using Archimedes' principle. To validate the value of the density, it is also calculated theoretically by the rule of mixture.

\section{Sliding Wear Testing}

For determining the behaviour of wear of the composites, a sliding wear test is done on the advanced Rotary Tribometer manufactured by Ducom, Bangalore, as shown in Fig. 2. The wear tests are conducted as per ASTM G99. The specimens for wear test are prepared as per ASTM G99, and one sample is shown in Fig. 3.

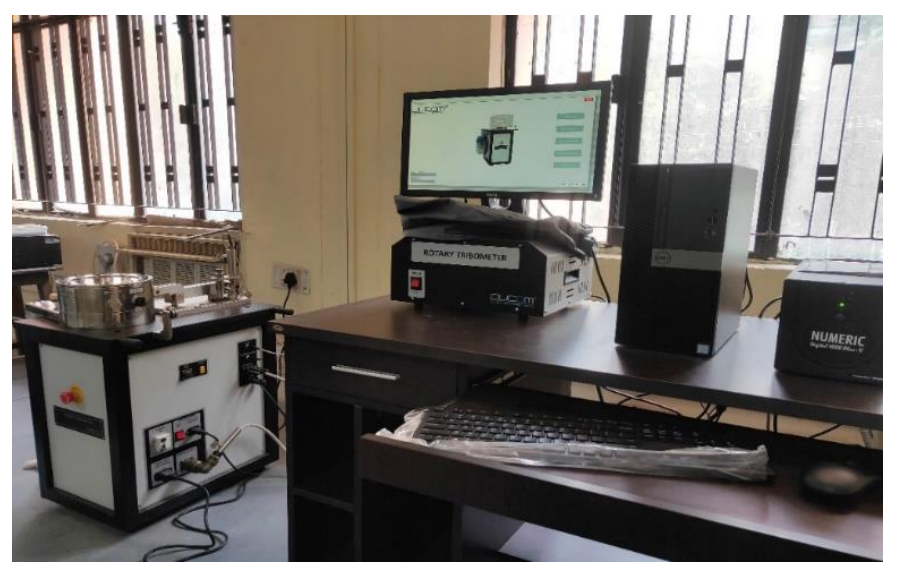

Figure 2: Pin-on-Disc Rotary Tribometer.

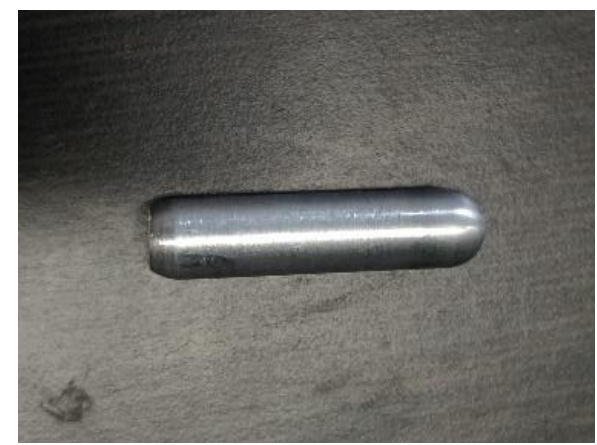

Figure 3: Sample for Wear Test.

\section{RESULTS AND DISCUSSION}

\section{Elemental Analysis}

The elemental composition of matrix Al7075 and reinforcement $\mathrm{B}_{4} \mathrm{C}$ are shown in Table 1 and Table 2[13].

Table 1: Chemical Analysis of Al7075 Alloy

\begin{tabular}{|c|c|c|c|c|c|c|}
\hline Elements & $\mathrm{Zn}$ & $\mathrm{Mg}$ & $\mathrm{Cu}$ & $\mathrm{Fe}$ & $\mathrm{Cr}$ & $\mathrm{Al}$ \\
\hline \% wt. & 5.8 & 2.4 & 1.5 & 0.2 & 0.2 & Balance \\
\hline
\end{tabular}


Table 1: Chemical Analysis of $\mathrm{B}_{4} \mathrm{C}$ Powder $50 \mu \mathrm{m}$

\begin{tabular}{|c|c|c|c|c|c|c|c|}
\hline Elements & Purity & Boron & Carbide & O & N & Si & Ni \\
\hline \% wt. & 99.9 & 77.2 & 22.3 & $<0.1$ & $<0.08$ & $<0.1$ & $<0.01$ \\
\hline
\end{tabular}

\section{Mechanical Properties}

The tensile strength, impact strength, and hardness are shown in Table 3[13].

Table 2: Mechanical Properties of Al7075 Alloy and Its Composites

\begin{tabular}{|c|c|c|c|}
\hline Materials & Ultimate Tensile Strength (MPa) & Impact Strength (Joule) & Brinell Hardness Number (BHN) \\
\hline M0 & 129.776 & 64.5 & 85.1 \\
\hline M6 & 196.325 & 42.0 & 109.4 \\
\hline M8 & 206.235 & 35.5 & 112.6 \\
\hline M10 & 217.365 & 27.5 & 118.8 \\
\hline M12 & 232.781 & 25.0 & 125.2 \\
\hline
\end{tabular}

\section{Density}

The density of the fabricated composites with different volume fractions of reinforcements is shown in Fig. 4. From Fig. 4, it is observed that with an increase in the volume fraction of reinforcement, the density of composite decreases. The value of experimental density is lower than that of the theoretical value of composite except for $0 \%$ reinforcement, i.e. pure aluminium alloy.

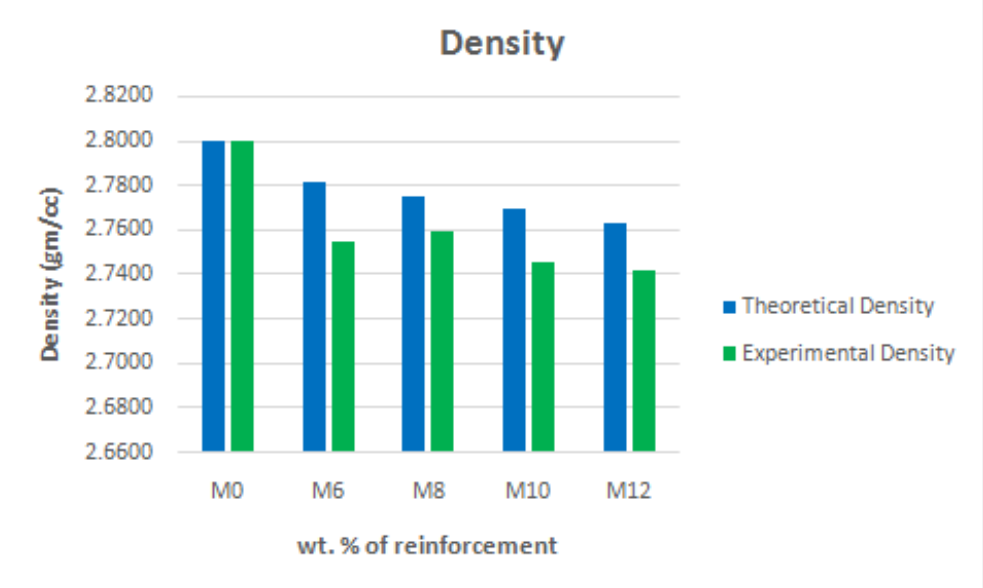

Figure 4: Density Variations of Pure Al7075 and its Composites.

\section{Wear Test}

The sliding wear test of the fabricated composites was performed at sliding velocities $1.5 \mathrm{~m} / \mathrm{s}, 2.5 \mathrm{~m} / \mathrm{s}$, and $3.5 \mathrm{~m} / \mathrm{s}$ for a total sliding distance of $2 \mathrm{~km}$. At each sliding velocity, the load was $10 \mathrm{~N}, 15 \mathrm{~N}$, and $20 \mathrm{~N}$ for each experiment. During the wear test at $10 \mathrm{~N}, 15 \mathrm{~N}$ and $20 \mathrm{~N}$ load, the mass loss after $2 \mathrm{~km}$ sliding distance was measured. The mass loss at $10 \mathrm{~N}$, $15 \mathrm{~N}$ and $20 \mathrm{~N}$ are shown in Fig. 5, Fig. 6 and Fig. 7 respectively. From Fig. 5, Fig. 6 and Fig. 7, it is observed that the mass loss increases with an increase in sliding velocity. It is also observed that there is a decrease in wear that is mass loss with an increase in the volume fraction of the reinforcement $\left(\mathrm{B}_{4} \mathrm{C}\right)$. 


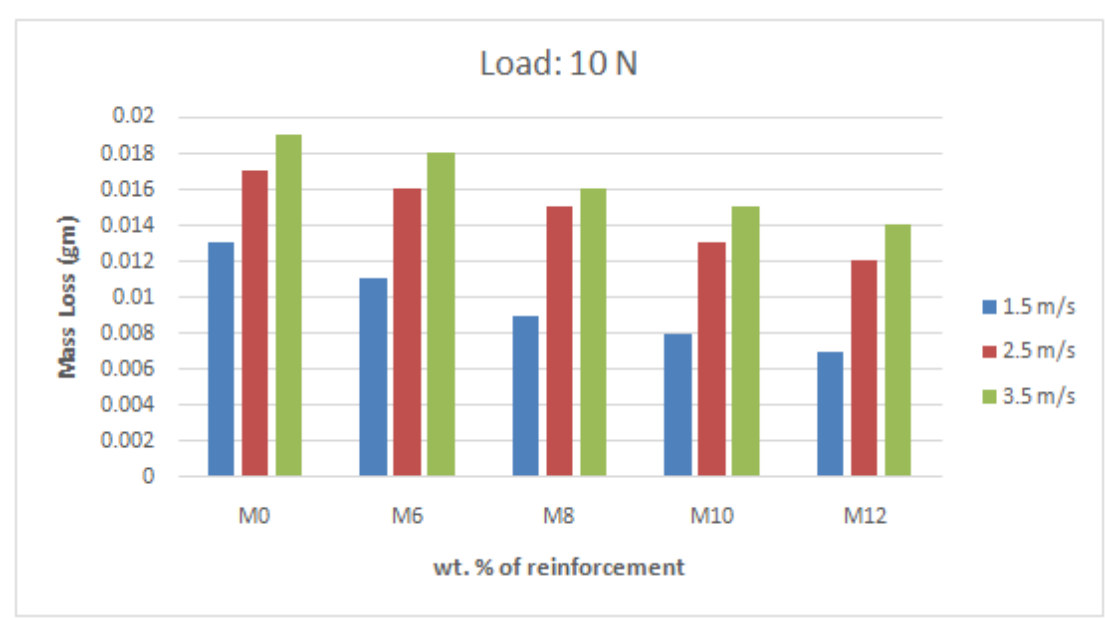

Figure 5: Mass Loss of Pure Al7075 and its Composites with Load 10 N.

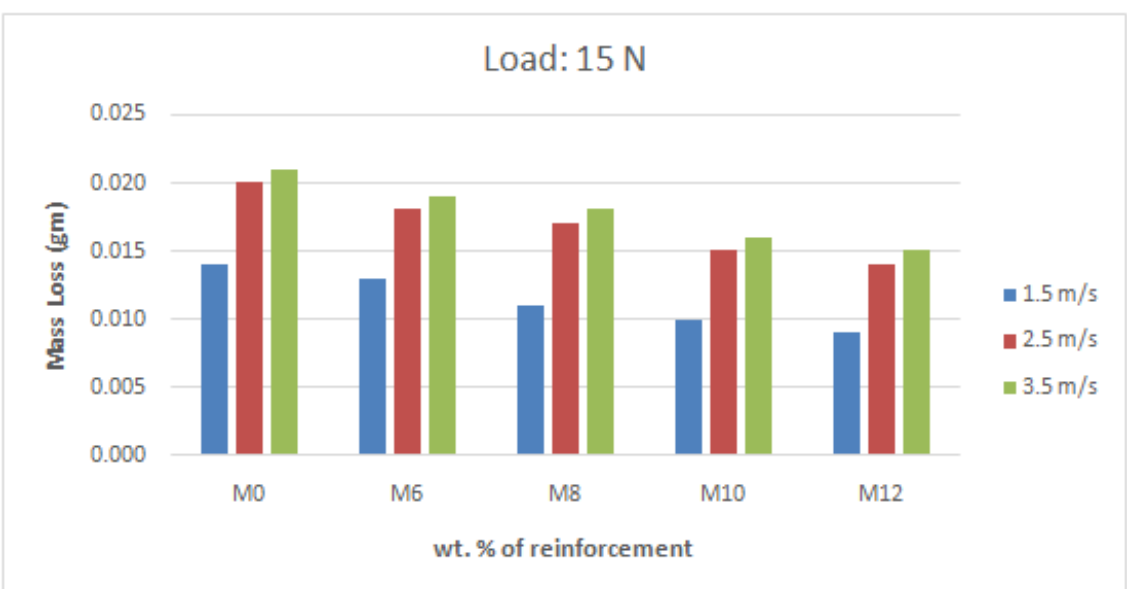

Figure 6: Mass Loss of Pure Al7075 and its Composites with Load 15 N.

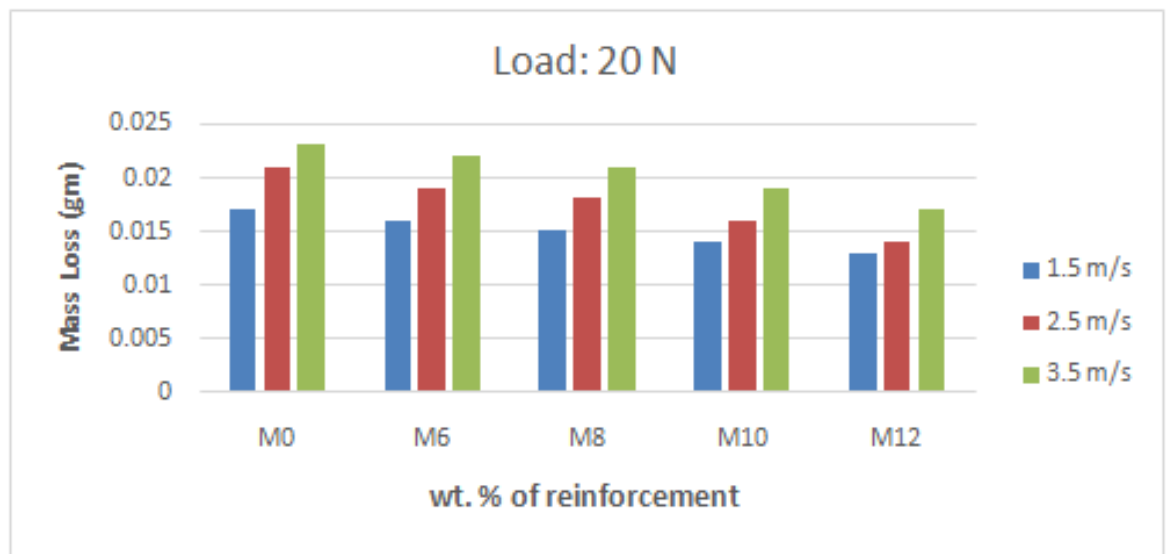

Figure 7: Mass Loss of Pure Al7075 and its Composites with Load 20 N.

\section{Wear Rate}

The wear rate of the fabricated composites is shown in Fig. 8, Fig. 9 and Fig. 10 at velocities $1.5 \mathrm{~m} / \mathrm{s}, 2.5 \mathrm{~m} / \mathrm{s}$ and 3.5 $\mathrm{m} / \mathrm{s}$ respectively. 


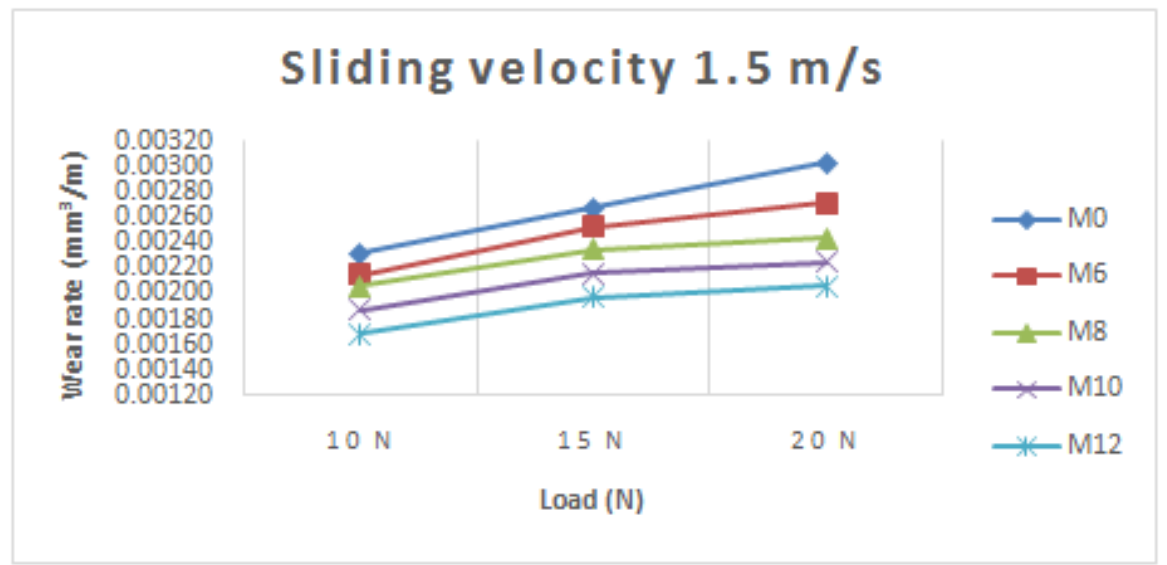

Figure 8: Wear Rate of Pure Al7075 and its Composites with 1.5 m/s.

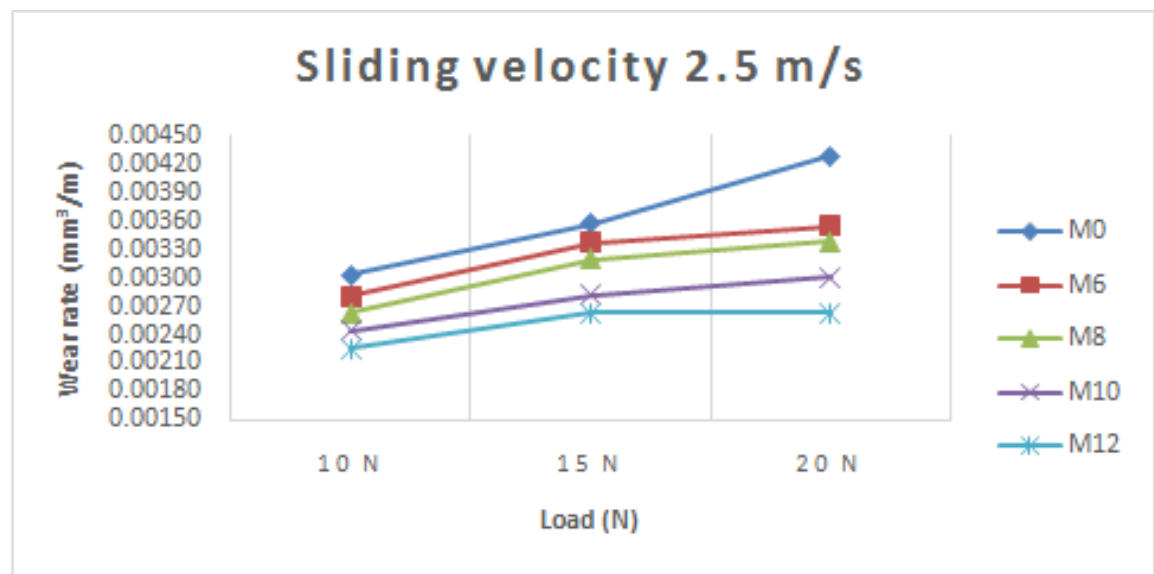

Figure 9: Wear Rate of Pure Al7075 and its Composites with 2.5 m/s.

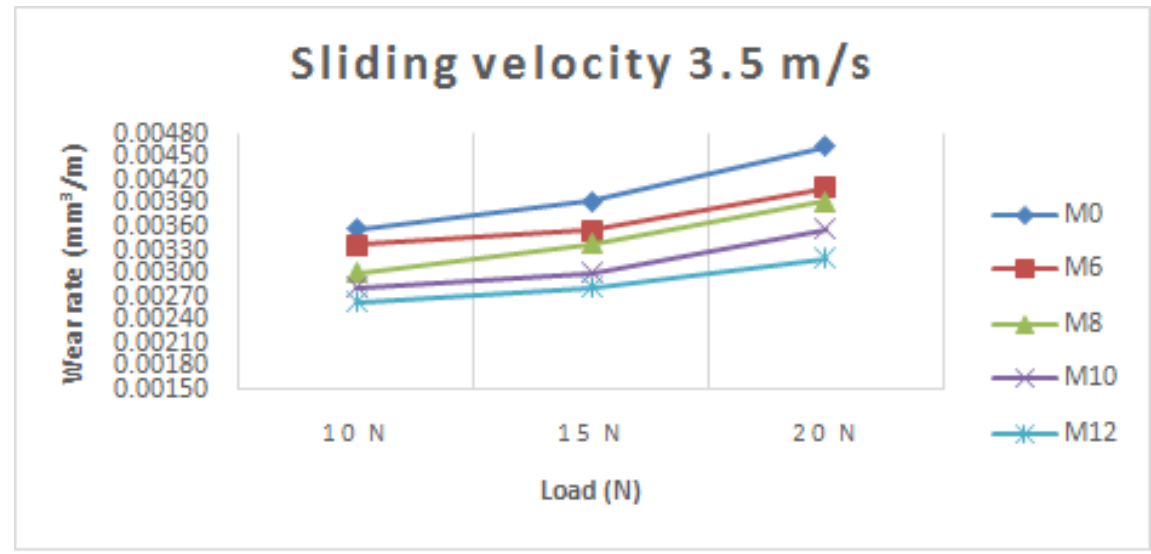

Figure 10: Wear Rate of Pure Al7075 and its Composites with 3.5 m/s. 


\section{Effect of Load}

From the result, it is observed that the load is affecting the wear behaviour of the developed composites. From Fig. 8, Fig. 9, and Fig. 10, it is found that the mass loss is increasing with increasing the load. This finding is in agreement with that reported by Radhika and Priyanka [7] and Rao et al. [9].

\section{Effect of Velocity}

From the result of the wear rate, it is observed that there is variation in wear rate with the varying velocity of sliding. From Fig. 5, Fig. 6 and Fig. 7 it is observed that there is an increase in mass loss with increasing the velocity which is similar to the finding of Suresh et al., it is also observed that there is a decrease in mass loss with increase in the weight per cent of the reinforcement at a given sliding velocity.

\section{Effect of Strength and Hardness}

The ultimate tensile strength of the composite was found to be highest with $12 \% \mathrm{~B}_{4} \mathrm{C}$. So it can be said that the wear rate is affected by the strength of the material. With an increase in strength, there is an increase in wear resistance. It is also found that wear behaviour is also depending on the hardness of the material. With increasing hardness, there is an increase in wear resistance of the composites, and these are similar to the finding reported by Lara et al. [8].

\section{CONCLUSIONS}

From the investigation of wear behaviour of $\mathrm{Al} 7075 / \mathrm{B}_{4} \mathrm{C}$ composites, the following findings are observed:

- Tensile strength and hardness increase with an increase in weight $\%$ of the reinforcement.

- Experimental density is lower than the theoretical one.

- The wear rate is decreasing with an increase in weight $\%$ of the reinforcement $\left(\mathrm{B}_{4} \mathrm{C}\right)$ at a constant velocity.

- The wear rate is increasing with the increase in load at a constant velocity.

- The wear rate is increasing with an increase in the sliding velocity at constant load. However, the increase in wear rate at velocities from $1.5 \mathrm{~m} / \mathrm{s}$ to $2.5 \mathrm{~m} / \mathrm{s}$ is decreasing with an increase in the weight $\%$ of the reinforcement.

\section{ACKNOWLEDGMENTS}

The authors wish to thank the Department of Mechanical Engineering, KNIT, Sultanpur, U. P., India for providing facilities and necessary support in conducting experiments.

The authors are thankful to the World Bank Technical Education Quality Improvement Programme Phase-III (WB TEQIP-III) Grant/Scheme No. 2038 Project of KNIT, Sultanpur, U. P., India also for financial assistance.

\section{CONFLICTS OF INTEREST}

The authors declare no conflicts of interest. 


\section{REFERENCES}

1. Murthy, N. V, Reddy, A. P., Selvaraj, N., and Rao, C. S. P., 2015, “A Review on Fabrication of Aluminium Alloy Based Metal Matrix Nano Composites through Ultrasonic Assisted Casting,” Metall. Mater. Eng. Res., 1(2), pp. 1-8.

2. Jokhio, H. M., Panhwar, M. I., and Unar, M. A., 2011, "Manufacturing of Aluminum Composite Material Using Stir Casting Process,” MEHRAN Univ. Res. J. Eng. Technol., 30(1), pp. 53-64.

3. Suresh, S., Gowd, G. H., and Devakumar, M. L. S., 2020, "Wear Behavior of $\mathrm{Al} 7075 / \mathrm{Al}_{2} \mathrm{O}_{3} / \mathrm{SiC}_{\mathrm{H}} \mathrm{Hybrid} \mathrm{NMMC}$ 's by Stir Casting Method," Mater. Today Proc., 24, pp. 261-272.

4. Rajesh, A. M., Kaleemulla, M. K., and Doddamani, S., 2019, "Effect of Heat Treatment on Wear Behavior of Hybrid Aluminum Metal Matrix Composites,” Tribol. Ind., 41(3), pp. 344-354.

5. Ajr, N., and Dennison, M. S., 2018, "Wear and Friction Characteristics of Aluminium Matrix Composites Wear and Friction Characteristics of Aluminium Matrix Composites Reinforced With Flyash/Cu/Gr Particles,” Chemtech, 11(01), pp. 121-133.

6. Daniel, A. A., Murugesan, S., Manojkumar, M., and Sukkasamy, S., 2017, "Dry Sliding Wear Behaviour of Aluminium 5059/SiC/MoS 2 Hybrid Metal Matrix Composites,” Mater. Res., 20(6), pp. 1697-1706.

7. Radhika, N., and Priyanka, M. L. V., 2017, "Investigation of Adhesive Wear Behaviour of Zirconia Reinforced Aluminium Metal Matrix Composite,” Eng. Sci. Technol., 12(6), pp. 1685-1696.

8. Deaquino-lara, R., Soltani, N., Bahrami, A., Gutiérrez-castañeda, E., and García-sánchez, E., 2015, “Tribological Characterization of Al7075-Graphite Composites Fabricated by Mechanical Alloying and Hot Extrusion,” J. Mater., 67, pp. 224-231.

9. Rao, V. R., Ramanaiah, N., and Sarcar, M. M. M., 2016, "Dry Sliding Wear Behavior of TiC-AA7075 Metal Matrix Composites," IJASE, 14(1), pp. 27-37.

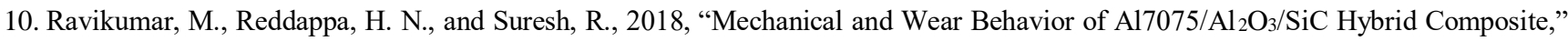
Mater. Today Proc., 5(2), pp. 5573-5579.

11. Chandra, B., and Shankar, H. S. S., 2018, "Effect Of Heat Treatmenton Dry Sand Abrasive Wear Behavior Of Al7075-Albite Particulate Composites,” Mater. Today Proc., 5, pp. 5968-5975.

12. Radhika, N., Vidyapeetham, A. V., and Raghu, R., 2015, "Evaluation of Dry Sliding Wear Characteristics of LM 13 Al/B 4 C Composites,” Tribol. Ind., 37(1), pp. 20-28.

13. Singh, K. M., and Chauhan, A. K., 2020, "Comparison of Mechanical and Microstructural Examination of Al7075 Composites Reinforced with Micro and Nano B 4 C," Int. J. Mech. Eng. Technol., 11(4), pp. 8-15. 

